\title{
Ser cuidador em serviço residencial terapêutico: fragilidades e potencialidades na prática assistencial
}

\section{Being a caregiver in a therapeutic residency service: fragilities and potentialities in assistance practice}

\section{Ser cuidador en servicio de residencia terapéutico: fragilidades y potencialidades en la práctica asistencial}

Silva, Amanda Stefani Torquato da ${ }^{1}$; Ribeiro, Genêsis Brito²; Santos, Laércio Lucas Xavier dos ${ }^{3}$; Buriola, Aline Aparecida ${ }^{4}$

Como citar este artigo: Silva AST, Ribeiro GB, Santos LLX, Buriola AA. Ser cuidador em serviço residencial terapêutico: fragilidades e potencialidades na prática assistencial. J. nurs. health. 2019;9(1):e199107

\section{RESUMO}

Objetivo: identificar as fragilidades e potencialidades vivenciadas pelos cuidadores na prática assistencial dos serviços de residência terapêutica. Método: pesquisa qualitativa realizada por meio de entrevista semiestruturada, com 12 cuidadores dos de seis Serviços de Residências Terapêuticas do Oeste Paulista, cujos dados foram tratados por análise de conteúdo de Bardin. Resultados: emergiram duas categorias, fragilidades na prática de ser cuidador em serviço de residência terapêutica: superando limites e as potencialidades na prática de ser cuidador em serviço de residência terapêutica: uma conquista nas relações interpessoais. Considerações finais: os cuidadores têm dificuldades em promover atividades a fim de ressocializar às pessoas com transtorno mental, decorrente da sobrecarga de trabalho com as atividades domésticas da residência e o vínculo com o morador é um facilitador na assistência aos mesmos.

Descritores: Saúde mental; Cuidadores; Transtornos mentais.

\section{ABSTRACT}

Objective: to identify the weaknesses and potentialities experienced by caregivers in the care practice of therapeutic residency services. Method: qualitative research carried out through a semistructured interview with 12 caregivers of the six Residual Therapy Services from the west of São Paulo, whose data were treated by Bardin 's content analysis. Results: two categories emerged, weaknesses in the practice of being a caregiver in a therapeutic residency service: surpassing limits and the potentialities in the practice of being a caregiver in a therapeutic residency service: an

\footnotetext{
1 Enfermeira. Especialista em Gestão da Qualidade e Segurança do Paciente. Serviço Nacional de Aprendizagem Comercial (SENAC) de Presidente Prudente/SP. E-mail: amandastefani_torquato@hotmail.com http://orcid.org/0000-0002-8049-5415

2 Enfermeira. Universidade do Oeste Paulista (UNOESTE). E-mail: genesisbribeiro@hotmail.com http://orcid.org/0000-0002-1057-066X

3 Enfermeiro. Hospital Regional de Presidente Prudente/SP. E-mail: lucasxavier2010@hotmail.com http://orcid.org/0000-0001-8004-326X

4 Enfermeira. Doutora em Enfermagem. Universidade do Oeste Paulista (UNOESTE). E-mail: aliburiola@gmail.com http:// orcid.org/0000-0003-1232-6115
} 


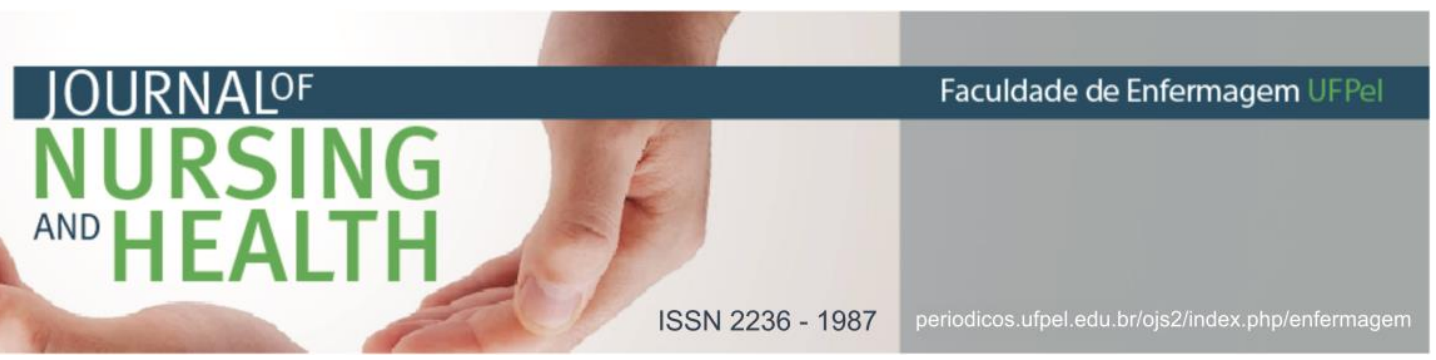

achievement in interpersonal relationships. Final considerations: caregivers have difficulties in promoting activities in order to re-socialize people with mental disorders, due to the overload of work with the domestic activities of the residence and the bond with the resident is a facilitator in the care of them.

Descriptors: Mental health; Caregivers; Mental disorders.

\section{RESUMEN}

Objetivo: identificar las fragilidades y potencialidades vivenciadas por los cuidadores en la práctica asistencial de los servicios de residencia terapéutica. Método: investigación cualitativa realizada por medio de entrevista semiestructurada, con 12 cuidadores de los de seis Servicios de Residencias Terapéuticas del Oeste Paulista, cuyos datos fueron tratados por análisis de contenido de Bardin. Resultados: surgieron dos categorías, fragilidades en la práctica de ser cuidador en servicio de residencia terapéutica: superación de límites y las potencialidades en la práctica de ser cuidador en servicio de residencia terapéutica: una conquista en las relaciones interpersonales. Consideraciones finales: los cuidadores tienen dificultades para promover actividades para resocializar a las personas con trastorno mental, debido a la sobrecarga de trabajo con las actividades domésticas de la residencia y el vínculo con el morador es un facilitador en la asistencia a los mismos.

Descriptores: Salud mental; Cuidadores; Trastornos mentales.

\section{INTRODUÇÃO}

A história da reforma psiquiátrica brasileira é compreendida como um processo de construção, iniciada na década de 1960, atuando na desconstrução de saberes e práticas psiquiátricas, referentes aos manicômios. Os hospitais psiquiátricos eram vistos por sua assistência hospitalocêntrica, exclusão, segregação e retificação da pessoa com transtorno mental. ${ }^{1}$

O novo modelo proposto é o psicossocial, as ações não são voltadas à doença, mais ao indivíduo e suas competências, substituindo os hospitais psiquiátricos por redes de serviços territoriais de atenção psicossocial, possibilitando a desinstitucionalização, de modo a reinseri-los em suas comunidades, desenvolvendo autonomia e fortalecendo vínculos. ${ }^{1}$

As mudanças na política de saúde mental brasileira ganham impulso com a promulgação da Lei Federal 10.216, de 06 de abril 2001, que dispõe sobre a proteção e os direitos das pessoas com transtornos mentais e reestrutura 0 modelo assistencial em saúde mental no Brasil em curso desde a década de 1990. Este novo modelo estabelece a reestruturação da assistência em saúde mental como o conjunto de transformações de práticas, saberes, valores culturais e sociais em torno da pessoa com transtorno mental. ${ }^{2}$

A Política Nacional de Saúde Mental (PNSM) orienta o fechamento de leitos psiquiátricos, reduzindo-os progressivamente, favorece a ampliação e o fortalecimento de uma rede territorializada de serviços de atenção em Saúde Mental, constituída principalmente por Centros de Atenção Psicossocial (CAPSs) e pelos Serviços Residenciais Terapêuticos (SRTs), incluindo ações de Saúde Mental na Atenção Básica, como também orienta sobre a atenção integral a usuários de substâncias psicoativas. Com a aprovação da $n^{\circ}$ 3.088/ Portaria 2.011, 


\section{NURSING \\ AND}

institui-se a Rede de Atenção Psicossocial (RAPS) e estabelece os critérios de organização e implementação em todo o país, integrando a saúde mental em todos os níveis e pontos de atenção no Sistema Único de Saúde (SUS). ${ }^{3}$

Neste contexto, surgem as SRTs, sendo este momento marcado por um conjunto de transformações nos conhecimentos teóricos, nas estratégias de intervenção, nos valores culturais e sociais que se materializam no processo interventivo dos serviços de atenção a saúde mental no Brasil. 0 SRT, substitutivo ao modo manicomial asilar de assistência, é uma das estratégias de atenção à saúde mental preconizada pela PNSM. ${ }^{4}$

Segundo a legislação, artigo $3^{\circ}$, aos SRTs em Saúde Mental cabem: assegurar assistência aos portadores de transtornos mentais que possuem uma alta dependência institucional, impossibilitados de usufruir da autonomia social, não possua vínculos familiares e de moradia, com longas permanências ao tratamento psiquiátrico no regime hospitalar, e que apresentam condições de reinserção na sociedade. ${ }^{5}$

As SRTs, conforme definição do SUS são casas localizadas no espaço urbano, custeadas pelo Governo Federal, geridas por governos estaduais e/ou municipais, destinadas à reabilitação de pessoas com transtornos mentais na comunidade, com o objetivo de reconstruir os seus vínculos sociais perdidos. Os SRTs possuem espaços de moradia/habitação, um lar para pessoas com vínculos familiares
ISSN 2236 - 1987

rompidos, promovendo a reinserção dos mesmos na sociedade. ${ }^{2}$

Os SRTs se dividem em duas modalidades: SRT I, é designada às pessoas que não possuem vínculos familiares e sociais, e com internação de longa permanência. 0 serviço disponibiliza um espaço de construção de autonomia e reinserção social. Deve alojar no máximo oito moradores, e deverá estar associada a um serviço de saúde mental de referência, com suporte técnico profissional necessário ao serviço de residência. A segunda modalidade SRT II, atua na moradia para pessoas com maior grau de dependência, que necessitam de cuidados intensivos específicos, necessitam de apoio técnico diário e pessoal constante, deve acolher no máximo 10 moradores. ${ }^{6}$

Cada residência possui um perfil diferenciado, se adapta as necessidades e as preferências de seus moradores, devendo contar sempre com suporte profissional habilitado às demandas. Esse suporte caracteriza um profissional técnico e o cuidador. 0 cuidador do SRT é um integrante da equipe convive maior parte do tempo com o morador, sendo fundamental no acompanhamento e no desenvolvimento da proposta da reforma. Porém, esse profissional não é devidamente preparado para tal função e, dessa forma, faz-se necessário entender a relevância deste profissional, mas desde que bem preparado para tal. ${ }^{7}$

$\mathrm{Na}$ categoria trabalhista, referente ao cuidado ou assistência proporcionada pelos diversos tipos de moradias, destaca-se um trabalhador pouco reconhecido pela 
regulamentação legal dos serviços de moradia, e escasso na literatura específica, trata-se do cuidador em saúde. ${ }^{8}$

O cuidador em saúde mental deve ter capacitação específica em reabilitação psicossocial é muito importante para a formação continuada desses profissionais como, por exemplo, a participação em treinamentos e capacitações com abordagem a temas relacionados à atuação do profissional de saúde mental, relacionamento interpessoal, controle e administração de medicamentos, acolhimento e supervisão dos moradores nas atividades cotidianas, atuação em situações de crises e emergências. ${ }^{4}$

A atribuição do cuidador é acompanhar e auxiliar o indivíduo a se cuidar, fazendo pela pessoa somente as atividades que ela não consiga executar com total autonomia. Evidencia-se que algumas atividades não são legalmente estabelecidas na rotina do cuidador, singularmente na área de enfermagem. ${ }^{8}$

A rara referência ao cuidador profissional na regulamentação legal do SRT e na literatura específica revela que há uma lacuna relacionada ao assunto dificultando a identificação das demandas relacionadas ao trabalho de cuidador, sendo este um ponto premente para a realização de pesquisas que busquem identificar como se estabelece a dinâmica de trabalho desta população específica. Sendo assim, este estudo tem como questão de pesquisa: Quais são as fragilidades e potencialidades para o cuidador ao prestar assistência ao morador do Serviço de Residência
Terapêutica? Para tanto, este estudo teve como objetivo identificar as fragilidades e potencialidades vivenciadas pelos cuidadores na prática assistencial dos serviços de residência terapêutica.

\section{MÉTODO}

Pesquisa do tipo descritivaexploratória, com abordagem qualitativa, realizada em seis SRT implantadas em um município do Oeste Paulista.

As SRTs foram implantadas gradativamente, sendo a primeira inaugurada em dezembro de 2015. Atualmente, existem seis delas, cada uma contém 10 moradores, número máximo de pacientes permitidos por SRT II. Na coordenação das Residências Terapêuticas há uma responsável Técnica, uma Coordenadora em Saúde Mental e uma Diretora de Saúde de um Consórcio Intermunicipal do Oeste Paulista, que faz a gestão das casas. Esta gestão é compartilhada com a prefeitura municipal que conta com serviço de manutenção às residências e serviços de apoio aos funcionários e moradores. A coordenação frequenta a casa, avalia e prepara o cuidador de forma continuada para o desenvolvimento de seu trabalho. Todas as Residências foram abertas mediante processo jurídico.

Ao todo são 48 cuidadores nas seis residências terapêuticas, dois por turno, intercalando 12 horas de trabalho por 36 de descanso. Desempenham atividades de assistência em geral ao morador (banho, higiene, medicação, etc.), limpeza da casa, preparo da 


\section{JOURNALOF \\ NURSING \\ aNOHEALTH}

alimentação e participam da ressocialização.

Como participantes do estudo foram elencados 12 cuidadores contratados pelo município para atuarem nestes SRTs. Como critério de inclusão foram inseridos aqueles cuidadores que trabalhavam, mediante contrato do município, há no mínimo um mês nos SRTs.

0 instrumento de coleta de dados foi um roteiro de entrevista semiestruturado, contendo as seguintes questões norteadoras: conte detalhadamente como foi iniciar as atividades assistências no SRT; descreva com detalhes, quais são as fragilidades e as potencialidades que envolvem as atividades assistências no SRT.

Para caracterizar melhor os participantes da pesquisa também foram coletados dados, tais como: sexo, idade, escolaridade, tempo de atuação no SRT, formação específica em saúde mental e se exerce outra atividade laboral.

As entrevistas foram previamente marcadas por contato telefônico, realizadas nas SRTs com duração de 30 minutos por cuidador. No ambiente estavam os moradores interagindo com os cuidadores, e houve interferências consideráveis, em alguns momentos foi necessário pausar a gravação. As falas dos entrevistados foram registradas em gravador digital, também foi realizado um diário de campo, no qual os pesquisadores anotaram suas percepções e as reações dos participantes durante a entrevista, para melhor subsidiar a análise dos dados. Para processamento dos dados,
ISSN 2236 - 1987

logo após a realização das entrevistas, as falas dos participantes foram transcritas na íntegra.

As análises dos dados obtidos pelos depoimentos foram tratadas por meio da análise de conteúdo de Bardin, que consiste em um conjunto de instrumentos metodológicos em constante aperfeiçoamento que se aplicam em discursos extremamente diversificados. Essa técnica de análise de dados oscila entre dois pólos do rigor da objetividade e da fecundidade da subjetividade. A fim de se constituir as categorias temáticas, a autora propõe as seguintes etapas: préanálise; exploração do material; tratamento dos resultados e interpretações. ${ }^{9}$

$\mathrm{Na}$ pré-análise, fases de organização dos documentos ocorreram três leituras flutuantes que tinham como propósito a escolha dos relatos, formulação de hipóteses, a escolha dos índices de análise e elaboração de indicadores categóricos para fundamentar a interpretação dos dados; a fase de exploração do material consistiu em quatro leituras sistematizadas que tinham como intencionalidade fazer agrupamentos e associações que respondessem aos objetivos do estudo e, assim, construir as categorias analíticas. Por fim, a fase de tratamento dos resultados compreendeu o momento em que foram realizadas as inferências e a interpretação dos resultados encontrados, discutindo-os com base na literatura. ${ }^{9}$

Esta pesquisa foi realizada seguindo todos os preceitos éticos vigentes na Resolução 466/2012. Os dados foram coletados após a 
ISSN 2236 - 1987

aprovação do comitê de ética em pesquisa da Universidade do Oeste Paulista sob o parecer 3857 e Certificado de Apresentação para Apreciação Ética (CAAE) 68108217.2.0000.5515. Todos os participantes assinaram o Termo de Consentimento Livre e Esclarecido em duas vias, e para garantir o anonimato dos participantes, os trechos/excertos dos depoimentos foram acompanhados pela sigla "E", seguida de um número arábico correspondente à sequência da entrevista.

\section{RESULTADOS E DISCUSSÃO}

Os cuidadores não possuíam formação técnica em saúde mental, sendo que 10 pertenciam ado sexo feminino. A idade variou entre 21 e 55 anos. O tempo de atuação como cuidadores em SRTs foi em média um ano e quatro meses. A seguir são descritos os temas, de acordo com os dados encontrados.

Fragilidades na prática de ser cuidador em SRT: Superando Limites

É extremamente difícil descrever de forma concisa e direta o papel de cuidadores nos serviços de saúde mental, porém cuidador em saúde teve seu reconhecimento como profissão em 10/01/2011, data que foi criado o código 5162-20 da Classificação Brasileira de Ocupações, reconhecimento atendido pelo Ministério do Trabalho que definiu como cuidador em saúde o profissional que cuida de bebês, crianças, jovens, adultos e idosos, seguindo um plano de trabalho pré-estabelecidos por instituições especializadas ou pelo responsável legal, sendo este responsável por cuidar do bem-estar geral do seu cliente. ${ }^{10}$

Sendo assim, esta categoria irá apresentar as construções de cuidadores sobre suas dificuldades no que concerne os cuidados domésticos e pouco apoio de profissionais específicos da saúde como médicos e enfermeiros.

Os depoimentos a seguir evidenciam a fragilidade enfrentada pelos cuidadores em exercer suas atividades assistências no que diz respeito à prática de reabilitação terapêutica em saúde mental.

O papel de cuidador mesmo eu acho que ele é pouco realizado, é mais o serviço de casa mesmo, então não exerce a função de cuidador e acaba prejudicando, porque não tem o tempo ideal para eles. (E1)

Eu acho que os cuidadores deviam cuidar deles, auxiliar no banho, na alimentação, fazer dinâmicas, e aqui acabamos fazendo tudo, a gente cozinha, lava, limpa, somos domésticas. É a gente cuida mais da casa do que propriamente deles. Foge um pouco do projeto, porque não tem dinâmica, não tem tempo [...]. (E7)

Nas falas das entrevistadas, é possível inferir que a escassez de tempo para atividades de cuidado é fator de frustração da sua atuação como cuidador, uma vez que as atividades domésticas se sobressaem à dinâmica assistencial de reabilitação psicossocial. 


\section{JOURNALOF \\ NURSING \\ ANO HEALTH}

ISSN 2236 - 1987

se permitindo praticar as atividades esperadas.

As oficinas terapêuticas são atividades grupais de socialização, expressão e inserção social, visando à integração social dos cidadãos. Mediante a isto, é perceptível a importância de atividades terapêuticas a fim de proporcionar maior qualidade de vida aos moradores dos SRTs. ${ }^{12}$

A questão de termos que dar mais atenção para a casa do que para eles, isso é extremamente cansativo [...] pegamos os que têm mais condições e tentamos ensinar eles a fazerem coisas básicas, como lavar louça, passar a vassoura, mas algo que realmente façam melhorar não fazemos, muito pela ausência de tempo. [...]. (E5)

$\mathrm{Na}$ fala do entrevistado, o esforço dos cuidadores em tentar inserir a pessoa com transtorno mental no cotidiano de atividades da SRT, sendo esta talvez uma estratégia de promover a autonomia desses indivíduos e ao mesmo tempo, encontrar tempo e condições para execução de atividades terapêuticas.

A sobrecarga do cuidador é considerada então como um conflito resultante do trabalho em lidar com a incapacidade mental e a dependência física do indivíduo que necessita de atenção e cuidados, juntamente com problemas físicos e mentais que sofrem os cuidadores de pessoas com enfermidades, afetando atividades cotidianas, relacionamentos sociais e equilíbrio emocional. Desta forma, percebe-se que a sobrecarga é decorrente da ausência de tempo, e 


\section{JOURNALOF \\ NURSING \\ AND HEALTH}

também do grau de dependência relacionada à assistência aos pacientes com transtornos mentais. ${ }^{13}$

[...] Se tivesse uma cozinheira, uma pessoa para limpar a casa, a gente se dedicaria só a eles, poderia ir passear andar um pouco, levar para fazer atividades, ficar em atividade o dia inteiro com eles, além de ajudar eles a se cuidar [...]. (E11)

Estamos vulneráveis por falta de funcionários, porque o certo seria ser três. Não dois, é raro acontecer situações imprevistos? É! Mas acontece. (E3)

De acordo com os excertos, é possível evidenciar a necessidade de ampliação no quantitativo de funcionários nos SRTs, pois as atividades extras de cuidados domésticos interferem na assistência integral ao morador, visto que o tempo é preenchido pela demanda do lar. Os relatos trazem a vontade de ter um momento de lazer e socialização com os moradores, para isto, contar com funcionários a mais, possibilita que os cuidadores tenham uma aproximação efetiva com a pessoa com transtorno mental e um olhar voltado ao mesmo nas ações do cuidado.

A Portaria $\mathrm{n}^{\circ} 3.090$, de 23 de dezembro de 2011, prevê que "cada módulo residencial deverá contar com cuidadores de referência e um profissional técnico de enfermagem. Para cada grupo de 10 (dez) moradores orienta-se que a SRT seja composta por 05 (cinco) cuidadores em regime de escala e 01 (um) profissional técnico de enfermagem diário. Esta equipe deve estar em consonância com a equipe
ISSN 2236 - 1987

técnica do serviço de referência".6:1 Desta forma é perceptível que ter um quantitativo adequado sanaria alguns problemas presentes na assistência nos SRTs. ${ }^{6}$

No começo, quando eu entrei, eu senti falta da enfermagem, porque eu não sabia medir uma pressão, dextro [medicamento] eu fazia porque eu tenho minha irmã diabética em casa e vejo ela fazendo, e a parte um pouco de farmácia que mexe com medicação, até eu pegar o que tinha da medicação que tinha que dar ou deixar de dar [...]. (E1)

Nós sentimos falta de um médico ou um enfermeiro específico para a residência, porque é uma segurança a mais, uma equipe de suporte. (E3)

Já nos depoimentos dos entrevistados, fica evidente que dentre os cuidados básicos de assistência estão verificação de sinais vitais, procedimentos de teste de glicemia [dextro] e medicações, no entanto, faz-se necessário uma capacitação e atualização, contando com apoio profissional específico. 0 apoio de profissionais específicos gera impacto na confiança dos cuidadores e os deixa seguro para desempenhar suas funções.

O matriciamento é um novo modo de produzir saúde em que duas ou mais equipes, num processo de construção compartilhada, criam uma proposta de intervenção pedagógico-terapêutica. Atua como apoio profissional específico citado pelos cuidadores, no qual alavancaria a qualidade da assistência prestada. Cabe ao CAPS, 


\section{JOURNALOF \\ NURSING \\ ${ }^{\text {MNOHEALTH }}$}

como o maior exemplo de matriciamento relacionado à saúde mental, dar suporte; discutir e intervir conjuntamente; supervisionar e capacitar às unidades de atenção básica e o Programa Saúde da Família e aos SRTs. ${ }^{14}$

[...] é melhor ficar em só uma residência por causa do vínculo que formamos com os pacientes, quando se roda demais de residência em residência acaba que temos dificuldade com os costumes de cada paciente. (E5)

Facilita muito ficar em uma residência, sem muitos rodízios, porque vamos criando um vínculo com eles e eles se apegam muito $a$ nós, e adquirem confiança, assim como nós já os conhecemos, estamos lidando com eles, sabe qual o hábito de cada um, do que eles gostam e o que não gostam tudo fica mais fácil [...]. (E11)

Nos depoimentos foi ressaltada a importância do vínculo, pois a aproximação com o morador permite um contato de confiança, facilitando a assistência, com a convivência é possível conhecer o paciente em suas particularidades, tornando assim as ações mais assertivas. Ficou nítido a importância do vínculo entre moradores e cuidadores, a quebra desse vínculo através da rotatividade diminui a confiança dos cuidadores em prestar assistência e predispõe o paciente a não aceitar as condutas dos cuidadores.

Além da inclusão da pessoa com transtorno mental nos serviços de saúde, é preciso vínculo entre ela e o
ISSN 2236 - 1987

profissional que oferece assistência nos serviços, pois assim se estabelece uma relação de confiança no cuidado, ou seja, recebe uma escuta que abrange 0 trabalho baseado nos pressupostos do cuidado integral e humanizado à saúde mental. 0 rodízio de profissionais deve ser visto de diversas formas, primeiro ele é importante para que cada cuidador tenha uma perspectiva diferente de todos os pacientes e dessa forma venha a aprender a prestar assistência em diversas situações, para realizar um trabalho efetivo é necessária à confiança e o vínculo com os mesmos, em específico tratando-se de pacientes com transtornos mentais é interessante um tempo maior de adaptação dos profissionais em cada SRT. ${ }^{15}$

\section{Potencialidades na prática de ser cuidador em SRT: Uma conquista nas Relações Interpessoais}

Vínculo, isso é o que facilita o trabalho de um cuidador nos serviços de saúde, o fato de se importar com o próximo, de haver dedicação, a existência de cuidados humanizados, são esses os suportes para que o cuidador preste assistência com qualidade e que torna seu trabalho mais fácil. Acredita-se se que não só o paciente se torna dependente do cuidador, mas também estabelece vínculo tão íntimo com o paciente, que cuidar the proporciona prazer, bemestar, satisfação e contentamento. ${ }^{16}$

Sendo assim, esta categoria irá apresentar as construções de cuidadores sobre suas facilidades na atuação em um SRT, principalmente no que concerne ao processo de empatia, 


\section{JOURNALOF \\ NURSING \\ ANO HEALTH}

ISSN 2236 - 1987

boas relações profissionais e satisfação na visualização dos resultados relacionados ao cuidado ofertado.

Elas [moradoras] são bem receptivas. Elas têm um certo carinho, e a gente vai descobrindo as coisas junto com elas, o que elas gostam de comer, de assistir e daí a gente vê que elas ficam melhor com a gente sabendo delas [...]. (E3)

A gente cria um vínculo de afetividade, de confiança, tanto da parte deles quanto da minha e cada um tem um jeito, uma particularidade, tudo se resume nisso, afetividade, de confiar em você, de também ter sentimentos por você, aquele tipo de amizade, confiança principalmente[...]. (E9)

Nos depoimentos dos entrevistados é possível inferir que os cuidadores percebem que 0 afeto e o vínculo estabelecido com os moradores dos SRTs é algo peculiar no processo de cuidado. A empatia é um fator intrínseco que contribui para uma visão holística voltada ao outro, colaborando com ações de humanização, se tratando de saúde mental, o cuidador tem papel fundamental para estabelecer conscientização sobre 0 assunto.

Atualmente existem discussões relacionadas à humanização em saúde mental que se iniciou com a luta antimanicomial, quando foram extintos os castigos físicos e mentais e os abusos medicamentosos como fins terapêuticos, iniciando os direitos dos pacientes em falar e serem ouvidos e principalmente, pela modificação das relações dos profissionais de saúde entre si e suas relações com os pacientes. ${ }^{17}$

Ressaltamos ainda, que no depoimento é utilizado o termo 'moradoras', a partir do momento que passam a residir em Residência Terapêutica passam a se chamar os moradores e não mais os pacientes, proporcionando o respeito aos seus direitos como cidadão e como sujeito em condição de viver em comunidade. ${ }^{4}$

Para mim, os meus companheiros de trabalho ajudaram demais, nunca tive problemas com eles, sempre que precisei de ajuda eles me auxiliaram e eu acho que é isso que facilitou quando eu comecei a trabalhar até hoje [...]. (E5)

Aqui você aprende de tudo. A adaptação foi rápida, mas o importante foi o relacionamento interpessoal com o colega de trabalho, uma boa pessoa faz o serviço fluir [...]. (E10)

As relações interpessoais estabelecidas no trabalho foram apontadas pelos entrevistados como facilitadoras da adaptação profissional e da construção das ações de cuidado. Ter uma boa relação no ambiente laboral contribui com as ações prestadas ao morador, sendo satisfatório estar neste local de trabalho.

O clima organizacional prediz o estresse e o desempenho. Os fatores promoção, recompensa e benefícios; relacionamento com os pares e relacionamento com a chefia se correlacionaram negativamente e 


\section{ISSN 2236 - 1987}

positivamente, refletindo diretamente à satisfação, desempenho, taxa de absenteísmo e ao estresse dos profissionais. ${ }^{18}$

A experiência em hospital psiquiátrico ajudou muito no processo de adaptação na residência, é satisfatório e eu gosto de trabalhar aqui, se eu não gostasse falava para vocês. Desde quando eu entrei me adaptei bem [...]. (E8)

Bem, é um lugar agradável, lugar bom se de trabalhar. Tenho conhecimento da área por conta do meu pai, e frequentava os mesmos ambientes que eles [moradores] moravam antes [...]. (E6)

Nos excertos dos entrevistados, a convivência prévia com o adoecimento mental, por meio de 30 anos de atuação em hospital psiquiátrico ou como cuidadora do pai com transtorno mental, parece emergir como facilitadora do processo de adaptação a função de cuidador em saúde mental, pois o estigma de loucura está presente no conceito de indivíduos que não tiveram contato com esse público. Para quem tem a experiência na área, torna-se válido e proveitoso, visto que já conhecem as particularidades de um portador de transtorno mental.

Um olhar voltado para o paciente com transtorno mental vem de uma mudança na percepção sobre o sujeito e sobre o próprio campo da saúde mental, a experiência e compreensão sobre a assistência ideal a esses pacientes norteiam o repensar das práticas profissionais. Essas experiências permitem a compreensão que o cuidado não se faz em via única, mas através da troca de experiências e saberes dos diferentes profissionais da saúde e, dos pacientes. ${ }^{2}$

Eu gosto de fazer festa, esses dias teve festa caipira e juntou todas as residências, foi legal, e vieram as famílias, parentes dos cuidadores, e isso é bom para eles, aproxima mais, $e$ isso melhora muito o comportamento deles eu acho que essa é a forma da gente ver que faz bem para eles [...]. (E7)

$O$ reconhecimento do trabalho de cuidador surge no depoimento como algo que contribui para a continuidade do esforço profissional. Este, por meio de ações de aproximação social busca consolidar suas ações assistências e perceber a satisfação dos moradores emerge como facilitador do processo de esforço profissional.

Os fatores que levam à satisfação no trabalho referem-se às condições físicas, salários, benefícios e segurança no trabalho. Por sua vez, fatores que estimulam a motivação no trabalhador são fatores que estão focados na tarefa (o trabalho em si) e sua implementação incluindo a liberdade para procurar características pessoais formas únicas de alcançar os resultados, criar e inovar. Eles incluem sentimentos pessoais de crescimento e reconhecimento profissional, focado na autorrealização do indivíduo para tarefas desafiadoras. Os cuidadores motivados irão apresentar maior desempenho, maior satisfação na prestação de assistência aos pacientes e esses sentimentos positivos são gerados nas expressões de felicidades 


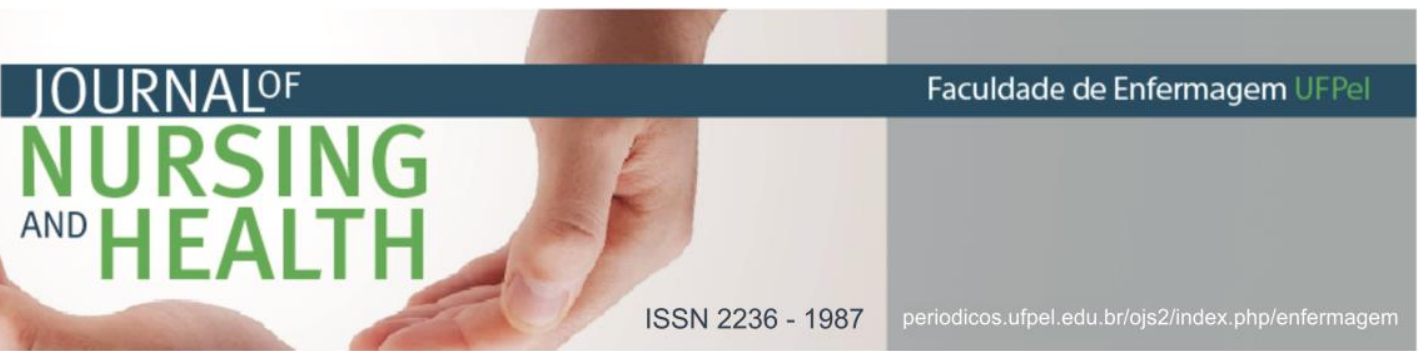

de todos os pacientes para com os cuidadores. ${ }^{19}$

Para os cuidadores é gratificante contribuir com a melhora do paciente e assim fazer parte da ressocialização e inserção na sociedade, quebrando o tabu criado pela ausência de informação e aproximação com a pessoa com transtorno mental. 0 cuidador estabelece uma assistência humanizada e segundo preconiza a Reforma Psiquiátrica, de uma forma ampla, sendo ela biopsicossocial, torna-se mediador entre morador/paciente e comunidade, através da reinserção social. Neste estudo, é possível inferir que o cuidador é um ator social, articulando ações que incentivam e estimulam a autonomia do morador, permitindo-lhe o retorno para a sociedade.

\section{CONSIDERAÇÕES FINAIS}

O estudo identificou como um dos fatores que dificultam a dinâmica assistencial dentro dos serviços de residência terapêutica, a sobrecarga com atividades domésticas, questão essa que dificulta 0 processo assistencial integral de cuidador. Como facilidade o vínculo que se cria entre cuidadores e pacientes é um dos fatores que motivam a realização de uma assistência de qualidade, esse vínculo pode vir a ser um passo de suma importância para a consolidação da reabilitação psicossocial da pessoa com transtorno mental.

0 estudo foi realizado em SRTs de um município do interior do Oeste Paulista, desta forma não é possível generalizar e potencializar seus achados nos quais indicam que 0 cuidado humanizado em saúde mental

não está de acordo aos pressupostos da Reforma Psiquiátrica. Seria interessante agregar a equipe de profissionais dos SRTs um profissional que trabalhe com o serviço doméstico, a fim de diminuir a sobrecarga perante os cuidadores e permitindo aos mesmos um tempo propício para desenvolver os trabalhos e ações de reabilitação psicossocial.

Buscando manter a educação continuada e a supervisão clínica longitudinal, poderia ser instaurada uma visita de rotina da equipe multiprofissional do CAPS, a fim de sanar possíveis dúvidas dos cuidadores e os capacitar a uma melhor assistência de cuidados em saúde mental, tendo em vista que essa atenção já ocorre, ou deveria ocorrer, também com os familiares/cuidadores dos usuários do CAPS ou outros profissionais da rede de atenção em saúde. Esta visita de rotina trará também uma visão holística de atenção à saúde mental, voltado desta vez aos cuidadores, propiciando também a otimização do tempo dispendido nesta visita, já que estaria assim resolvendo duas questões de uma só vez.

\section{REFERENCIAS}

1 Costa JP, Jorge MSB, Coutinho MPL, Costa EC, Holanda A. A reforma psiquiátrica e seus desdobramentos: representações sociais dos profissionais e usuários da atenção psicossocial. Psicol. saber soc. [Internet]. 2016[acesso em 2018 nov 28];5(1):35-45. Disponível em: https: / /www.e-

publicacoes.uerj.br/index.php/psisabersocial/article/view/15855/17903 


\section{JOURNALOF \\ NURSING \\ ANO HEALTH}

ISSN 2236 - 198

Disponível

em: http: / /bvsms.saude.gov.br/bvs/saude legis/gm/2011/prt3090_23_12_2011.h $\mathrm{tml}$

7 Barbosa BCAL. O cuidador no serviço residencial terapêutico [monografia]. Florianópolis (SC): Universidade Federal de Santa Catarina; 2014[acesso em 2018 nov 28]. Disponível em: https: / / repositorio.ufsc.br/bitstream /handle/123456789/167214/Bruna\%20 Cristina\%20Aparecida\%20de\%20Lima\%2 OBarbosa\%20-\%20PSICO\%20\%20TCC.pdf?sequence=1\&isAllowed=y

8. Neves ES, Souza MMT, Tavares CM, Vasconcelos CBS. O processo de trabalho dos cuidadores de saúde que atuam em residências terapêuticas. Revista Pró- UniverSus [Internet]. 2014[acesso em 2018 nov 28];05(1):216. Disponível em:http://editora.universidadedevass ouras.edu.br/index.php/RPU/article/ view/537/347

9. Silva AH, Fossá MIT. Análise de conteúdo: exemplo de aplicação da técnica para análise de dados qualitativos. Qualitas [Internet]. 2015[acesso em 2018 nov 28];17(1):114. Disponível em: http: / / revista.uepb.edu.br/index.php /qualitas/article/view/2113/1403

10 Ministério do Trabalho e Emprego (BR). Classificação Brasileira de Ocupações [Internet]. Brasília; 2011[acesso em 2018 nov 28]. Disponível em: http://www.mtecbo.gov.br/cbosite/p ages/pesquisas/BuscaPorTituloResulta do.jsf

11 Back V. Saúde mental dos cuidadores de idosos portadores da doença de Alzheimer [monografia]. 


\section{NURSING \\ AND}

Criciúma (SC): Universidade do Extremo Sul Catarinense; 2013[acesso em 2018 nov 28]. Disponível em: http:// repositorio.unesc.net/bitstrea $\mathrm{m} / 1 / 1779 / 1 /$ Vanessa\%20Back.pdf

12 Cruz MP, et al. Therapeutic workshops about mental health as a tool for psychosocial rehabilitation: perception of family members. Rev. enferm. UFPE on line. [Internet]. 2016[cited 2018 Nov 28];10(11):39964002. Available from: https: / / periodicos.ufpe.br/revistas/r evistaenfermagem/article/view/1148 2/13334

13 Boaventura LC, Borges HC, Ozaki AH. Avaliação da sobrecarga do cuidador de pacientes neurológicos cadeirantes adultos. Ciênc. Saúde Colet. [Internet]. 2016[acesso em 2018 nov 28];21(10):3193-202. Disponível em:

http://www.scielo.br/pdf/csc/v21n10 /1413-8123-csc-21-10-3193.pdf

14 Ministério da Saúde (BR). Guia prático de matriciamento em saúde mental [Internet]. Brasília; 2011[acesso em 2018 nov 28]. Disponível em: http://bvsms.saude.gov.br/bvs/public acoes/guia_pratico_matriciamento_sa udemental.pdf

15 Bessa JB, Waidman MAP. Family of people with a mental disorder and needs in psychiatric care. Texto \& contexto enferm. [Internet]. 2013[cited 2018 Nov 28];22(1):61-70. Available from: http://www.scielo.br/pdf/tce/v22n1/ 08.pdf

16 Vidigal FC, Ferrari RFR, Rodrigues DMMR, Marcon SS, Baldissera VDA, Carreira L. Satisfaction in caring for
ISSN 2236 - 1987

older adults with alzheimer's: perceptions of the family caregivers. Cogitare enferm. [Internet]. 2014[cited 2018 Nov 28];19(4):708-15. Available

from: https://revistas.ufpr.br/cogitare/arti cle/view/36739/23950

17 Carrara GLR, Moreira GMD, Facundes GM, Pereira R dos S, Baldo PL. Assistência de enfermagem humanizada em saúde mental: uma revisão da literatura. Revista Fafibe On-Line [Internet]. 2015[acesso em 2018 dez 07];8(1):86-107. Disponível em:

http://unifafibe.com.br/revistasonlin e/arquivos/revistafafibeonline/sumari o/36/30102015183642.pdf

18 Puente-Palacios KE, Pacheco EA, Severino AF. Clima organizacional e estresse em equipes de trabalho. Rev. psicol. organ. trab. [Internet]. 2013[acesso em 2018 nov 28];13(1):37$48 . \quad$ Disponível em: http://pepsic.bvsalud.org/pdf/rpot/v 13n1/v13n1a04.pdf

19 Giordani AT, Sonobe HM, Ezaias GM, Valério MA, Andrade D. Nursing adherence to hand hygiene according Herzberg's hygiene factors. Rev. enferm. UFPE on line. [Internet]. 2016[acesso em 2018 nov 28];10(2):600-7. Available from: https: / / periodicos.ufpe.br/revistas/r evistaenfermagem/article/viewFile/1 $0995 / 12350$

Data de submissão: $28 / 11 / 2018$

Data de aceite: 12/03/2019

Data de publicação: 20/03/2019 